\title{
Accuracy of transvaginal sonography in evaluation of abnormal uterine bleeding in perimenopausal women
}

\author{
Nicole Sequeira ${ }^{1}$, Shannon Fernandes ${ }^{2 *}$
}

\author{
${ }^{1}$ Student, Father Muller Medical College, Mangalore, Karnataka, India \\ ${ }^{2}$ Department of Obstetrics and Gynaecology, Father Muller Medical College, Mangalore, Karnataka, India
}

Received: 14 October 2019

Revised: 19 November 2019

Accepted: 05 December 2019

\author{
*Correspondence: \\ Dr. Shannon Fernandes, \\ E-mail: ferns4@rediffmail.com
}

Copyright: (C) the author(s), publisher and licensee Medip Academy. This is an open-access article distributed under the terms of the Creative Commons Attribution Non-Commercial License, which permits unrestricted non-commercial use, distribution, and reproduction in any medium, provided the original work is properly cited.

\begin{abstract}
Background: AUB is a commonly encountered complaint in peri- and postmenopausal women visiting OBG OPDs and accounts for about $70 \%$ of all gynaecological complaints. Key to management depends on the cause of AUB. Protocol has changed over the years from performing investigations randomly to a condition specific approach. This study aims to evaluate and compare the efficacy of transvaginal sonography and hysteroscopy in perimenopausal women with AUB and note its relation with histopathology.

Methods: A prospective study was conducted on 103 women of 40-55 years presenting to the OBG OPD of Father Muller Medical College Hospital, Mangalore. All patients underwent a transvaginal scan to note the endometrial thickness followed by a hysteroscopy and biopsy. Endometrium was sent for histopathology. Findings of these modalities were correlated.

Results: The diagnostic value of transvaginal sonography in relation to histopathology had a sensitivity and specificity of $33.33 \%$ and $95.95 \%$ for atrophic endometrium, $52.5 \%$ and $62.9 \%$ for proliferative, $29.41 \%$ and $79.41 \%$ for secretory, and $55.55 \%$ and $74.19 \%$ for hyperplastic. When compared to histopathology, hysteroscopy had a sensitivity and specificity of $100 \%$ and $92.3 \%$ for atrophic, $26.19 \%$ and $96.96 \%$ for proliferative, $27.07 \%$ and $98.59 \%$ for secretory, and $100 \%$ and $64.94 \%$ for hyperplastic endometrium. It had a sensitivity of $77.77 \%$ and a specificity of 92.92\% for endometrial polyps. Agreement between TVS and histopathology based on kappa co-efficient was fair for atrophic endometrium but poor for proliferative, secretory and hyperplastic endometrium. Agreement between hysteroscopy and histopathology was moderate for atrophic endometrium and for endometrial polyps. It was fair for proliferative, secretory and hyperplastic endometrium.

Conclusions: TVS seems to be a good initial method for evaluation of AUB. However, a subsequent hysteroscopy with biopsy is advisable to evaluate the cause of AUB.
\end{abstract}

Keywords: Abnormal uterine bleeding, Endometrial biopsy, Hysteroscopy, Perimenopause, Transvaginal scan

\section{INTRODUCTION}

Abnormal uterine bleeding is defined as any deviation from the normal menstrual cycle that includes change in regularity, frequency of menses, duration or amount of bleeding during or in between periods. ${ }^{1}$ It is one of the most common complaints for which a woman visits the gynaecologist and accounts for about $70 \%$ of all gynaecological consultations in peri and postmenopausal women. $^{2}$ The perimenopausal period is often characterised by menstrual irregularities which could include heavy bleeding, prolonged bleeding, missed 
periods, spotting between periods, etc. In most cases these irregularities are the result of normal hormonal changes that take place during the transition from the reproductive to the non-reproductive period. However, frequent episodes of irregular bleeding could be an indicator of an underlying pathology. In such cases, further evaluation is necessary to rule out serious pathology (such as carcinoma) and decide the course of management. ${ }^{3}$

The International Federation of Gynaecology and Obstetrics working group on menstrual disorders has proposed a classification (PALM-COEIN) for causes of AUB. ${ }^{4}$ AUB could occur due to structural (endometrial polyps, adenomyosis, fibroids, and hyperplasia/malignancy) or non-structural (coagulopathy, ovarian dysfunction, endometrial, iatrogenic) causes. Of note, AUB is the most common presentation of endometrial hyperplasia, a precursor of endometrial carcinoma. ${ }^{5}$ USG is recommended as a first line diagnostic tool in evaluating pathology in women with AUB. ${ }^{6}$ It is inexpensive, non-invasive and convenient. ${ }^{7}$ Hysteroscopy directly evaluates the uterine cavity and can accurately detect structural causes. ${ }^{8}$ Hysteroscopy is recommended to further evaluate the endometrium in women with AUB when the endometrial echo is normal on TVS. ${ }^{9}$

Hysteroscopy followed by endometrial biopsy is currently the gold standard for evaluating cases of AUB. Hysteroscopy, while a highly sensitive method, has the drawbacks of being invasive, more expensive and requiring anaesthesia. Cycling of the endometrium occurs based on the erratic production of oestrogen by the perimenopausal ovaries, and as a result, TVS needs to be carefully timed at the end of a bleeding episode so that the endometrial echo will be as thin as it is throughout the month. ${ }^{10}$ Therefore, there is a need for further research on the efficacy of TVS in evaluating AUB in perimenopausal women.

In undertaking this study, our aim was to estimate the accuracy of transvaginal sonography as a means to evaluate abnormal uterine bleeding in the perimenopausal age group taking hysteroscopic guided endometrial biopsy as the gold standard.

\section{METHODS}

A prospective study was conducted from June 2018 to May 2019 on women in the 40-55-year age group who presented to the OBG OPD of Father Muller Medical College Hospital, Mangalore with complaints of AUB after ethical clearance. 103 women were enrolled in the study after fulfilling the inclusion and exclusion criteria.

\section{Inclusion criteria}

- Women between 40 and 55 years of age with no identifiable pelvic pathology and having AUB.

\section{Exclusion criteria}

- Pregnancy

- Known genital malignancy

- Acute pelvic infection

- History of bleeding disorders

- Systemic causes of bleeding

- History of drug intake.

Written informed consent was obtained from each participant. A detailed history with emphasis on menstrual history was taken. Per speculum examination was done to rule out cervical and vaginal causes. Per vaginal examination was done to rule out uterine, cervical and adnexal pathology. After routine laboratory investigations, these patients were subjected to a transvaginal ultrasound scan using a $7.5 \mathrm{MHz}$ probe. Details regarding endometrial thickness and presence of any uterine or adnexal pathology were recorded. The participants were then subjected to a diagnostic hysteroscopy under short general anaesthesia. The hysteroscopic findings were documented and classified as atrophic, secretory, proliferative and hyperplastic. Any polyps, fibroids or locally unhealthy areas found on hysteroscopy were also recorded. Then a biopsy of the endometrium was done using a curette and the endometrial pattern was studied. The histopathologic findings of the endometrium obtained were classified as atrophic, secretory, proliferative, hyperplastic without atypia and hyperplastic with atypia.

\section{Statistical analysis}

The data collected was analysed to find the sensitivity, specificity, positive predictive value, negative predictive value and accuracy taking histopathology as the standard. Kappa co-efficient was used to determine the agreement between the three diagnostic techniques evaluated i.e. transvaginal sonography, hysteroscopy and histopathology.

\section{RESULTS}

It was observed in our study that AUB was common in multiparous women (87\%). $9 \%$ were primiparous and $4 \%$ were nulligravid (Table 1).

Table 1: Parity.

\begin{tabular}{|lll|}
\hline Parity & $\begin{array}{l}\text { No. of } \\
\text { women }\end{array}$ & $\begin{array}{l}\text { Percentage of women } \\
(\boldsymbol{\%})\end{array}$ \\
\hline P0 & 4 & 3.9 \\
\hline P1 & 9 & 8.7 \\
\hline P2 & 69 & 67 \\
\hline P3 and above & 21 & 20.4 \\
\hline Total & $\mathbf{1 0 3}$ & $\mathbf{1 0 0}$ \\
\hline
\end{tabular}

Among the different presentations of AUB, $70.9 \%$ of women complained of heavy menstrual bleeding alone 
while $17.5 \%$ complained of both heavy and prolonged menstrual flow. 5 women (4.9\%) had menstrual cycles lasting <21 days (polymenorrhea) and 2 women $(1.9 \%)$ complained of menstrual cycles lasting $>35$ days (oligomenorrhea). Only 1 woman had intermenstrual bleeding (Table 2).

Table 2: Presenting complaints.

\begin{tabular}{|lll|}
\hline Complaints & No. of women & $\%$ \\
\hline Heavy menstrual bleeding & 73 & 70.9 \\
\hline Prolonged menstrual bleeding & 1 & 0.9 \\
\hline $\begin{array}{l}\text { Heavy + prolonged menstrual } \\
\text { bleeding }\end{array}$ & 18 & 17.5 \\
\hline Intermenstrual bleeding & 1 & 0.9 \\
\hline Polymenorrhea & 5 & 4.9 \\
\hline Oligomenorrhea & 2 & 1.9 \\
\hline Postcoital bleeding & 2 & 1.9 \\
\hline Vaginal discharge & 1 & 0.9 \\
\hline
\end{tabular}

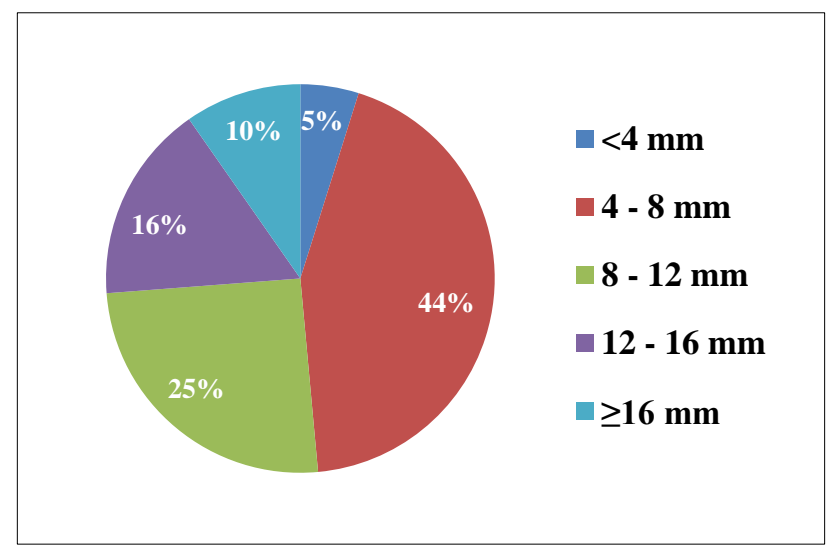

Figure 1: Endometrial thickness on TVS.

On transvaginal ultrasound, it was found that most of the women studied had an endometrial thickness of 4-8 mm $(43.7 \%)$ followed by endometrial thickness of $8-12 \mathrm{~mm}$ $(25.2 \%)$. Endometrial thickness of less than $4 \mathrm{~mm}$ was least common, found in only 5 participants. 17 women (16.5\%) had an endometrial thickness of 12-16 mm while 10 women $(9.7 \%)$ had an endometrial thickness of $16 \mathrm{~mm}$ or more (Figure 1).

Table 3: Causes of AUB (FIGO classification). ( $\neq \neq 103$ as some patients had more than 1 pathology)

\begin{tabular}{|lll|}
\hline FIGO class & No. of women & $\%$ \\
\hline Polyp & 21 & 20.4 \\
\hline Adenomyosis & 20 & 19.4 \\
\hline Leiomyoma & 54 & 52.4 \\
\hline Malignancy and hyperplasia & 16 & 15.5 \\
\hline Coagulopathy & 0 & 0 \\
\hline Ovulatory dysfunction & 5 & 4.8 \\
\hline Endometrial & 4 & 3.8 \\
\hline Iatrogenic & 1 & 1.0 \\
\hline Not yet classified & 3 & 2.9 \\
\hline
\end{tabular}

Of the 103 women studied, $54(52.4 \%)$ had leiomyomas, $20(19.4 \%)$ had adenomyosis and 21 (20.4\%) had endometrial polyps. 16 women $(15.5 \%)$ were diagnosed as having endometrial hyperplasia or carcinoma. 5 women were diagnosed with ovulatory dysfunction. Only 1 case of AUB could be attributed to iatrogenic causes and none were attributed to coagulopathy (Table 3 ).

Table 4: Distribution of hysteroscopic findings.

\begin{tabular}{|lll|}
\hline Hysteroscopic finding & Number & $\%$ \\
\hline Proliferative (dull pink) & 12 & 11.6 \\
\hline Secretory (bright pink) & 11 & 10.6 \\
\hline Hyperplasia (fluffy) & 44 & 42.7 \\
\hline Atrophic & 11 & 10.6 \\
\hline Polyps & 12 & 11.6 \\
\hline Fibroid & 1 & 0.9 \\
\hline Normal & 12 & 11.6 \\
\hline Total & 103 & 100 \\
\hline
\end{tabular}

On hysteroscopy it was found that the nearly $43 \%$ of the women studied had hyperplastic endometrium. $12 \%$ of women had proliferative endometrium. Secretory and atrophic endometrium were found in $11 \%$ of women each, 12 women were found to have endometrial polyps. In $12 \%$ of women, no abnormality was detected on hysteroscopy (Table 4).

Table 5: Endometrial pattern on histopathology.

\begin{tabular}{|lcl|}
\hline Type of endometrium & $\begin{array}{c}\text { No. of } \\
\text { cases }\end{array}$ & $\%$ \\
\hline Proliferative endometrium & 41 & 39.8 \\
\hline Secretory endometrium & 35 & 34.0 \\
\hline Endometrial hyperplasia without atypia & 10 & 9.7 \\
\hline Endometrial hyperplasia with atypia & 0 & 0 \\
\hline Atrophic endometrium & 3 & 2.9 \\
\hline Disordered proliferative endometrium & 2 & 1.9 \\
\hline Pill induced changes & 3 & 2.9 \\
\hline Endometrial polyps & 9 & 8.7 \\
\hline Total & 103 & 100 \\
\hline
\end{tabular}

The most common endometrial pattern was proliferative, seen in $41(39.8 \%)$ of the women studied. This was followed by a secretory endometrial pattern in $34 \%$ of women. An additional $2.9 \%$ of women showed disordered proliferative endometrium. 9.7\% showed endometrial hyperplasia without atypia while none of the women studied showed endometrial hyperplasia with atypia. Three women had atrophic endometrium on histopathology and three women showed pill induced changes (Table 5).

Out of 41 patients with endometrium showing proliferative phase, $51.2 \%$ showed ET of $4-8 \mathrm{~mm}, 26.8 \%$ showed ET of 8-12 mm, 12.2\% had ET of 12-16 mm and $4.8 \%$ had ET $>16 \mathrm{~mm}$. 
Table 6: Endometrial thickness on TVS versus histopathology.

\begin{tabular}{|llllllllll|}
\hline ET $(\mathbf{m m})$ & $\begin{array}{l}\text { No. of } \\
\text { cases }\end{array}$ & Proliferative & Secretory & $\begin{array}{l}\text { Hyperplasia } \\
\text { w/o atypia }\end{array}$ & $\begin{array}{l}\text { Hyperplasia } \\
\text { with atypia }\end{array}$ & Atrophic & $\begin{array}{l}\text { Disordered } \\
\text { proliferative }\end{array}$ & $\begin{array}{l}\text { Pill } \\
\text { induced }\end{array}$ & Polyps \\
\hline$<4$ & 5 & 2 & 2 & 0 & 0 & 1 & 0 & 0 & 0 \\
\hline $4-8$ & 45 & 21 & 16 & 5 & 0 & 1 & 0 & 0 & 2 \\
\hline $8-12$ & 26 & 11 & 11 & 0 & 0 & 1 & 1 & 0 & 2 \\
\hline $12-16$ & 17 & 5 & 3 & 3 & 0 & 0 & 1 & 2 & 3 \\
\hline$>16$ & 10 & 2 & 3 & 2 & 0 & 0 & 0 & 1 & 2 \\
\hline
\end{tabular}

Table 7: Diagnostic value of TVS in comparison to histopathology.

\begin{tabular}{|c|c|c|c|c|c|c|}
\hline $\begin{array}{l}\text { Histopathology } \\
\text { of endometrium }\end{array}$ & $\begin{array}{l}\text { Sensitivity } \\
(\%)\end{array}$ & $\begin{array}{l}\text { Specificity } \\
(\%)\end{array}$ & $\begin{array}{l}\text { Positive predictive } \\
\text { value }(\%)\end{array}$ & $\begin{array}{l}\text { Negative predictive } \\
\text { value }(\%)\end{array}$ & $\begin{array}{l}\text { Accuracy } \\
(\%)\end{array}$ & Kappa \\
\hline Atrophic & 33.33 & 95.95 & 20 & 2.06 & 94.11 & 0.221 \\
\hline Proliferative & 52.5 & 62.9 & 47.72 & 67.24 & 58.82 & 0.151 \\
\hline Secretory & 29.41 & 79.41 & 41.66 & 69.23 & 62.74 & 0.095 \\
\hline $\begin{array}{l}\text { Hyperplasia/ } \\
\text { carcinoma }\end{array}$ & 55.55 & 74.19 & 17.24 & 94.52 & 72.54 & 0.148 \\
\hline
\end{tabular}

Table 8: Hysteroscopy and histopathology findings (no. of cases).

\begin{tabular}{|c|c|c|c|c|c|c|c|c|c|}
\hline \multirow{9}{*}{ 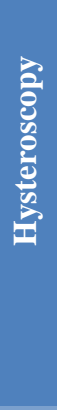 } & & \multicolumn{8}{|c|}{ Histopathology } \\
\hline & & Proliferative & Secretory & $\begin{array}{l}\text { Hyperplasia } \\
\text { w/o atypia }\end{array}$ & $\begin{array}{l}\text { Hyperplasia } \\
\text { with atypia }\end{array}$ & Atrophic & Polyps & $\begin{array}{l}\text { Pill } \\
\text { induced }\end{array}$ & $\begin{array}{l}\text { Disordered } \\
\text { proliferative }\end{array}$ \\
\hline & Dull pink & 11 & 1 & 0 & 0 & 0 & 0 & 0 & 0 \\
\hline & Bright pink & 1 & 10 & 0 & 0 & 0 & 0 & 0 & 0 \\
\hline & Fluffy & 18 & 11 & 10 & 0 & 0 & 1 & 2 & 2 \\
\hline & Bald & 6 & 2 & 0 & 0 & 3 & 0 & 0 & 0 \\
\hline & Polyps & 1 & 3 & 0 & 0 & 0 & 8 & 0 & 0 \\
\hline & Normal & 4 & 7 & 0 & 0 & 0 & 0 & 1 & 0 \\
\hline & Fibroids & 0 & 1 & 0 & 0 & 0 & 0 & 0 & 0 \\
\hline
\end{tabular}

Out of 35 patients with secretory endometrium $45.7 \%$ showed ET of $4-8 \mathrm{~mm}, 31.4 \%$ had ET of $8-12 \mathrm{~mm}, 8.6 \%$ had ET of $12-16 \mathrm{~mm}$ and another $5.7 \%$ had ET >16 mm.

Among 10 patients having hyperplasia without atypia on histopathology, $50 \%$ had ET of $4-8 \mathrm{~mm}, 30 \%$ had ET of $12-16 \mathrm{~mm}$ and $20 \%$ had ET of $>16 \mathrm{~mm}$.

A total 3 patients showed atrophic endometrium on histopathology, out of which 1 had an ET of $<4 \mathrm{~mm}, 1$ had an ET of 4-8 $\mathrm{mm}$ and $1 \mathrm{had}$ an ET of 8-12 $\mathrm{mm}$ (Table $6)$.

The diagnostic value of transvaginal sonography in relation to histopathology had a sensitivity and specificity of $33.33 \%$ and $95.95 \%$ for atrophic endometrium, $52.5 \%$ and $62.9 \%$ for proliferative, $29.41 \%$ and $79.41 \%$ for secretory, and $55.55 \%$ and $74.19 \%$ for hyperplastic (Table 7).

This was calculated on the presumption that atrophic is $<4 \mathrm{~mm}$, proliferative is $4-8 \mathrm{~mm}$, secretory is $8-12 \mathrm{~mm}$ and hyperplasia and carcinoma $>16 \mathrm{~mm}$.
On hysteroscopy, dull pink endometrium was found in 12 patients with 11 having proliferative endometrium on histopathology and 1 having secretory endometrium.

A total 11 patients had bright pink endometrium on hysteroscopy out of which 10 had a histopathology finding of secretory endometrium and 1 showed proliferative endometrium.

Fluffy endometrium was found in 44 patients on hysteroscopy. On histopathology, $41 \%$ of these patients had proliferative endometrium, $25 \%$ had secretory endometrium, $22.7 \%$ had hyperplasia without atypia and $2.3 \%$ had endometrial polyps.

Out of 11 women with bald endometrium on hysteroscopy, $54.5 \%$ had proliferative endometrium on histopathology, $18 \%$ had secretory endometrium and $27.2 \%$ had atrophic endometrium.

A total 12 patients were found to have polyps on hysteroscopy. $25 \%$ of these women showed secretory endometrium on histopathology, $8.3 \%$ showed proliferative endometrium and $66.7 \%$ showed polyps (Table 8). 
When compared to histopathology, hysteroscopy had a sensitivity and specificity of $100 \%$ and $92.3 \%$ for atrophic, $26.16 \%$ and $96.96 \%$ for proliferative, $27.07 \%$ and $98.59 \%$ for secretory, and $100 \%$ and $64.94 \%$ for hyperplastic endometrium. It had a sensitivity of $77.77 \%$ and a specificity of $92.92 \%$ for endometrial polyps (Table 9).

Table 9: Diagnostic value of hysteroscopy in comparison to histopathology.

\begin{tabular}{|lllllll|}
\hline $\begin{array}{l}\text { Histopathology } \\
\text { of endometrium }\end{array}$ & $\begin{array}{l}\text { Sensitivity } \\
(\%)\end{array}$ & $\begin{array}{l}\text { Specificity } \\
(\%)\end{array}$ & $\begin{array}{l}\text { Positive predictive } \\
\text { value }(\%)\end{array}$ & $\begin{array}{l}\text { Negative predictive } \\
\text { value }(\%)\end{array}$ & $\begin{array}{l}\text { Accuracy } \\
(\%)\end{array}$ & Kappa \\
\hline Atrophic & 100 & 92.3 & 33.33 & 100 & 92.59 & 0.471 \\
\hline Proliferative & 26.19 & 96.96 & 84.61 & 67.36 & 69.44 & 0.265 \\
\hline Secretory & 27.07 & 98.59 & 90.9 & 72.16 & 74 & 0.308 \\
\hline Hyperplasia & 100 & 64.94 & 24.44 & 100 & 68.51 & 0.274 \\
\hline Polyps & 77.77 & 92.92 & 50 & 97.87 & 91.66 & 0.565 \\
\hline
\end{tabular}

Table 10: Agreement between the three methods of evaluation.

\begin{tabular}{|lll|}
\hline Pathology & Agreement between tests arrived at by kappa co-efficient \\
\cline { 2 - 3 } & Tvs and histopathology & Hysteroscopy and histopathology \\
\hline Atrophic & Fair & Moderate \\
\hline Proliferative & Poor & Fair \\
\hline Secretory & Poor & Fair \\
\hline Hyperplasia & Poor & Fair \\
\hline Polyps & & Moderate \\
\hline
\end{tabular}

The agreement between TVS and histopathology based on the kappa co-efficient was fair for atrophic endometrium but poor for proliferative, secretory and hyperplastic endometrium. The agreement between hysteroscopy and histopathology was moderate for atrophic endometrium and for endometrial polyps. It was fair for proliferative, secretory and hyperplastic endometrium (Table 10).

\section{DISCUSSION}

In this study $87 \%$ were multiparous. $61 \%$ were multiparous as per Kumari et al and $71 \%$ as per Patil et al. ${ }^{11,12}$ The most common indication for evaluation in our study was heavy menstrual bleeding in $70.9 \%$, which is in accordance with a study conducted by Bhatiyani et al, where $60 \%$ patients presented with heavy menstrual bleeding followed by postmenopausal bleeding (12\%) followed by intermenstrual bleeding $(11 \%)$ and heavy and prolonged menstrual bleeding $(10 \%)$ in that order. ${ }^{13}$ However only $0.9 \%$ of patients had intermenstrual bleeding in our study and $17.5 \%$ of women complained of heavy and prolonged menstrual bleeding. Srinivas concluded that $46 \%$ of patients presented with heavy menstrual bleeding, 34\% had increased cycle frequency (earlier called polymenorrhea) and $20 \%$ of them had presented with continuous bleeding. ${ }^{14}$
Heavy menstrual bleeding was the presenting complaint in several studies; Choudhary J et al, (50\%), Pillai SS $(46.5 \%)$, Arnold J et al (43.7\%). ${ }^{15-17}$

According to Choudhary $\mathrm{J}$ et al, other bleeding patterns were frequent bleeding (14\%), intermenstrual bleeding $(18 \%)$, heavy prolonged $(6 \%)$ and irregular bleeding $(12 \%){ }^{15}$

The most common pathology on USG was fibroids $(52.4 \%)$ followed by polyps $(20.4 \%)$, adenomyosis (19.4\%) and thickened ET (15.5\%). According to Mishra et al $12.5 \%$ had thickened ET, $10 \%$ adenomyosis and $18.3 \%$ had fibroids. ${ }^{18}$

On transvaginal sonography, $43.7 \%$ of women showed an endometrial thickness of $4-8 \mathrm{~mm}, 25.2 \%$ had a thickness of $8-12 \mathrm{~mm}, 16.5 \%$ had a thickness of $12-16 \mathrm{~mm}$, and $9.7 \%$ were found to have an endometrial thickness of more than $16 \mathrm{~mm}$. These values were in accordance with the study conducted by Srinivas et al, in which endometrial thickness of 4-8 mm, 8-12 mm, 12-16 mm and $>16 \mathrm{~mm}$ were seen in $28 \%, 32 \%, 20 \%$ and $10 \%$ of subjects respectively. ${ }^{14}$ However, only $4.8 \%$ of women in this study showed an endometrial thickness of less than 4 $\mathrm{mm}$ as against $10 \%$ of women seen in the Srinivas et al study. ${ }^{14}$ In most studies it revealed ET of $8 \mathrm{~mm}$ could be taken as cut off in perimenopausal women and in the present study similar findings were observed. 
In this study, the endometrial pattern on histopathology was found to be proliferative in $34 \%$ and atrophic in $2.9 \%$ which correlated well with the values obtained by Shobitha et al, i.e., $30.4 \%$ secretory and $1.8 \%$ atrophic. Additonally, secretory endometrium was found in $39.8 \%$, hyperplastic (without atypia) in $9.7 \%$ and hyperplastic (with atypia) in none of the patients. ${ }^{19}$ This was similar to the results of the Bhatiyani et al, study where $39 \%$ had secretory endometrium, $14 \%$ showed hyperplasia without atypia and $2 \%$ showed hyperplasia with atypia (Table 11). ${ }^{13}$

Table 11: Endometrial pattern on histopathology comparison between different studies.

\begin{tabular}{|lll|l|}
\hline & $\begin{array}{l}\text { Present } \\
\text { study }\end{array}$ & $\begin{array}{l}\text { Bhatiyani } \\
\text { et al }\end{array}$ & $\begin{array}{l}\text { Shobitha } \\
\text { et al }\end{array}$ \\
\hline Secretory & $39.8 \%$ & $39 \%$ & $20 \%$ \\
\hline Proliferative & $34 \%$ & $16 \%$ & $30.4 \%$ \\
\hline $\begin{array}{l}\text { Hyperplasia } \\
\text { without atypia }\end{array}$ & $9.7 \%$ & $14 \%$ & $45.4 \%$ \\
\hline $\begin{array}{l}\text { Hyperplasia with } \\
\text { atypia }\end{array}$ & $0 \%$ & $2 \%$ & - \\
\hline Atrophic & $2.9 \%$ & - & $1.8 \%$ \\
\hline
\end{tabular}

According to Srinivas et al, TVS in comparison with histopathology as a gold standard revealed a sensitivity and specificity of $100 \%$ and $68.42 \%$ for proliferative endometrium, $100 \%$ and $74.42 \%$ for secretory, $28.57 \%$ and $100 \%$ for hyperplastic endometrium, $0 \%$ and $100 \%$ for carcinoma and $0 \%$ and $100 \%$ for atrophic endometrium. ${ }^{14}$

Diagnostic value of hysteroscopy in comparison to histopathology gave a sensitivity and specificity of $100 \%$ and $86.84 \%$ for proliferative endometrium, $57.14 \%$ and $100 \%$ for secretory, $67.86 \%$ and $100 \%$ for hyperplastic endometrium according to Srinivas et al. For carcinoma and atrophic endometrium both sensitivity and specificity were $100 \% .^{14}$

According to Bhatiyani et al, diagnostic value of hysteroscopy in comparison to histopathology gave an average sensitivity and specificity of $97.78 \%$ and $34.55 \%$ respectively, which was different for different findings on histopathology report. ${ }^{13}$

In the study by Choudhary J, the sensitivity, specificity, PPV and NPV for endometrial hyperplasia on hysteroscopy was $72.72 \%, 94.87 \%, 88.88 \%, 92.5 \%$ respectively. ${ }^{15}$ Loverro et al, stated the sensitivity, specificity, positive predictive value and negative predictive value was 98\%, 95\%, 63\% and 99\%, respectively, for endometrial hyperplasia. ${ }^{20}$

In the present study, hysteroscopy detected polyps with a sensitivity of $77.77 \%$ and positive predictive value of $50 \%$ in contrast to the sensitivity of $0 \%$ and positive predictive value of $0 \%$ found by Srinivas et al. ${ }^{14}$
Specificity (92.92\%), negative predictive value (97.87\%) and accuracy $(91.66 \%)$ of hysteroscopy for the detection of polyps were high and similar results were obtained by Srinivas et al. ${ }^{14}$

Choudhary $\mathbf{J}$ et al, revealed the sensitivity, specificity, PPV, NPV was $100 \%$ for polyp and sub mucosal fibroid on hysteroscopy. ${ }^{15}$ Patil et al, revealed a sensitivity, specificity, positive predictive value and negative predictive value of hysteroscopy for endometrial polyp as $100,95.78,55.55$ and $100 \% .^{21}$

Using kappa coefficient an agreement test was done between hysteroscopy and histopathology and again between TVS and histopathology.

Table 12: Agreement between TVS and histopathology - comparison between studies.

\begin{tabular}{|llll|}
\hline Pathology & $\begin{array}{l}\text { Present } \\
\text { study }\end{array}$ & $\begin{array}{l}\text { Srinivas } \\
\text { et al }^{\mathbf{1 4}}\end{array}$ & $\begin{array}{l}\text { Bhatiyani } \\
\text { et al }^{13}\end{array}$ \\
\hline Proliferative & Poor & Moderate & Moderate \\
\hline Secretory & Poor & Moderate & Moderate \\
\hline Hyperplastic & Poor & Fair & Fair \\
\hline Atrophic & Fair & Poor & Poor \\
\hline Polyp & & Poor & Poor \\
\hline
\end{tabular}

The agreement between transvaginal sonography and histopathology was assessed using the kappa co-efficient and was found to be poor for proliferative, secretory and hyperplastic endometrium and fair for atrophic endometrium. In both the Srinivas et al, and the Bhatiyani et al, study, agreement was moderate for proliferative and secretory endometrium, fair for hyperplastic endometrium and poor for atrophic endometrium and endometrial polyps (Table 12). ${ }^{13,14}$

Table 13: Agreement between hysteroscopy and histopathology - comparison between studies.

\begin{tabular}{|llll|}
\hline Pathology & $\begin{array}{l}\text { Present } \\
\text { Study }\end{array}$ & $\begin{array}{l}\text { Srinivas et } \\
\text { al }\end{array}$ & $\begin{array}{l}\text { Bhatiyani } \\
\text { et al }{ }^{[13]}\end{array}$ \\
\hline Proliferative & Fair & Substantial & Substantial \\
\hline Secretory & Fair & Substantial & Substantial \\
\hline Hyperplastic & Fair & Substantial & Substantial \\
\hline Atrophic & Moderate & Perfect & \\
\hline Polyp & Moderate & Poor & Perfect \\
\hline
\end{tabular}

The agreement between hysteroscopy and histopathology based on kappa co-efficient was fair was proliferative, secretory and hyperplastic endometrium and moderate for atrophic endometrium and endometrial polyps. In the Srinivas et al and Bhatiyani et al, studies, the agreement was substantial for proliferative, secretory and hyperplastic endometrium. ${ }^{13,14}$ The agreement was perfect for atrophic endometrium and poor for endometrial polyps according to Srinivas et al. In contrast, the Bhatiyani et al, study found the agreement to be perfect for endometrial polyps (Table 13). 


\section{CONCLUSION}

Although TVS seems to be a good and practical initial method for evaluation of AUB, However, a subsequent hysteroscopy is advisable to completely evaluate the cause of AUB as it allows direct visualisation of the uterine cavity and permits a directed biopsy for histopathological examination.

\section{ACKNOWLEDGMENTS}

Authors would like to thank Mrs. Sucharitha Suresh for her help with statistical analysis.

Funding: No funding sources Conflict of interest: None declared

Ethical approval: The study was approved by the Institutional Ethics Committee

\section{REFERENCES}

1. Vilos GA, Tureanu V, Garcia M, Abu-Rafea B. The levonorgestrel intrauterine system is an effective treatment in women with abnormal uterine bleeding and anticoagulant therapy. J Minim Invasive Gynecol. 2009;16(4):480-4.

2. Mahajan N, Aggarwal M, Bagga A. Health issues of menopausal women in North India. J Mid-Life Health. 2012;3(2):84-7.

3. Derzko C. Perimenopausal dysfunctional uterine bleeding: physiology and management. J SOGC. 1997;19(6):589-600.

4. Munro MG, Critchley HO, Fraser IS, FIGO Menstrual Disorders Working Group. The FIGO classification of causes of abnormal uterine bleeding in the reproductive years. Fertil Steril. 2011;95(7):2204-8.

5. Shokouhi B. Role of transvaginal ultrasonography in diagnosing endometrial hyperplasia in pre- and postmenopause women. Niger Med J. 2015;56:353-6.

6. Goldstein SF, Zeltser I, Horan CK, Snyder JR, Schwartz LB. Ultrasonography-based triage for perimenopausal patients with abnormal uterine bleeding. Am J Obstet Gynecol. 1997;177:102-8.

7. Goyal BK, Gaur I, Sharma S, Saha A, Das NK. Transvaginal sonography versus hysteroscopy in evaluation of abnormal uterine bleeding. Med J Armed Forces India. 2015;71(2):120-5.

8. Taneja P, Duggal BS. Hysteroscopy: past, present and future. Med J Armed Force India. 2002;58:2937.

9. de Vries LD, Dijkhuizen FP, Mol BW, Brölmann HA, Moret E, Heintz AP. Comparison of transvaginal sonography, saline infusion sonography and hysteroscopy in premenopausal women with abnormal uterine bleeding. J Clin Ultrasound. 2000;28(5):217-23.

10. Goldstein S, Lumsden M. Abnormal uterine bleeding in perimenopause. Climacteric. 2017;20(5):414-20.

11. Kumari M. efficacy of USG and hysteroscopy in the evaluation of AUB. Int J Reprod Contracept Obst Gynecol. 2015;4(6):1926-35

12. Patil R, Patil RK, Andola SK, Laheru V, Bhandar M. Histopathological spectrum of endometrium in dysfuctional uterine bleeding. Int $\mathrm{J}$ Biol Med Res. 2013;4(1):2798-801.

13. Bhatiyani B, Dhumale S, Pandeeswari, Bashani D. Correlation between ultrasonographic, hysteroscopic and histopathological findings in patients with abnormal uterine bleeding. Int $\mathrm{J}$ Reprod Contracept Obstet Gynecol. 2018;7(8):3250-6.

14. Srinivas K, Kulkarni S. Comparison of efficacy of TVS and hysteroscopy with histopathology of the endometrium in evaluating perimenopausal $\operatorname{AUB}(\mathrm{O})$. MOJ Womens Health. 2017;4(6):153-8.

15. Choudhary J, Acharya V, Jain M. Evaluation of abnormal uterine bleeding with transvaginal sonography and hysteroscopy in perimenopausal women. Int J Reprod Contracept Obstet Gynecol. 2017;6(8):3607-13.

16. Pillai S. Sonographic and histopathological correlation and evaluation of endometrium in perimenopausal women with abnormal uterine bleeding. Int J Reprod Contracept Obstet Gynecol. 2014;3(1):113-7.

17. Arnold J, Saravanan S. A two-year clinicopathological study of non-gravid women with abnormal uterine bleeding in a rural tertiary care centre in Tamil Nadu: in concurrence with the FIGO recommendations. J Evolut Med Dent Sci. 2015;4(63):10990-1000.

18. Mishra S, Panda B. Efficacy of ultrasonography and hysteroscopy and their correlation with endometrial histopathology in a case of abnormal uterine bleeding in late reproductive age. Ann Int Med Den Res. 2018;4(5):OG10-4.

19. Shobitha G, Kumari V, Priya P, Sundari B. Endometrial study by TVS and It's correlation with histopathology in abnormal uterine bleeding. IOSR-J Dent Med Sci. 2015;14(4):21-32.

20. Loverro G, Bettocchi S, Cormio G, Nicolardi V, Porreca M, Pansini N, et al. Diagnostic accuracy of hysteroscopy in endometrial hyperplasia. Mauritas. 1996;25(3):185-91.

21. Patil S, Bhute S, Inamdar S, Acharya N, Shrivastava D. Role of diagnostic hysteroscopy in abnormal uterine bleeding and its histopathologic correlation. J Gynecol Endosc Surg. 2009;1(2):98-104.

Cite this article as: Sequeira N, Fernandes S.

Accuracy of transvaginal sonography in evaluation of abnormal uterine bleeding in perimenopausal women. Int J Reprod Contracept Obstet Gynecol 2020;9:18793. 